\title{
Kekerasan Produk Metalurgi Serbuk Berbahan Limbah Aluminium dengan Metode Kompaksi Bertahap
}

\author{
Hardness of Powder Metallurgy Products Made of Aluminum Waste Using \\ Gradual Compaction Method
}

\author{
IGAK Chatur Adhi W, AA Alit Triadi*, Made Wijana, I Made Nuarsa, I Made Mara \\ Jurusan Teknik Mesin, Fakultas Teknik, Universitas Mataram.
}

*Corresponding Author Email: alittriadi68@unram.ac.id

Manuscript received: 08-12-2020. Accepted: 26-10-2021

\begin{abstract}
ABSTRAK
Produk hasil dari proses metalurgi serbuk memiliki keunggulan dalam hal sifat mekanik dan sifat fisiknya. Rekayasa material dengan mencampurkan beberapa jenis serbuk logam sangat memungkinkan untuk dilakukan. Komposisi dari bahan proses metalurgi serbuk ini adalah campuran serbuk aluminium (80\%), serbuk tembaga $(15 \%)$ dan serbuk silicon karbida (5\%) berat kemudian dilakukan kompaksi dengan beban kompaksi secara bertahap, mulai beban 3 ton ditahan 3 menit, dilanjutkan beban 4 ton ditahan 3 menit dan terakhir beban 5 ton ditahan 3 menit dengan pemanasan awal (pre sinter) $125^{\circ} \mathrm{C}$. Sintering di dalam dapur dengan variasi temperatur yaitu $450^{\circ} \mathrm{C}, 500^{\circ} \mathrm{C}$ dan $550^{\circ} \mathrm{C}$ dan waktu sintering selama 60 menit. Pengujian yang dilakukan terhadap specimen adalah uji kekerasan dengan metode Rockwell (HRF). Hasil penelitian diperoleh kekerasan material tunggal memiliki kekerasan berkisar $35 \mathrm{HRF}$. Kekerasan material campuran pada temperatur sintering $450^{\circ} \mathrm{C}$ rata-rata sebesar $80 \mathrm{HRF}$. Adapun kekerasan material campuran pada temperatur sintering $500^{\circ} \mathrm{C}$ ratarata sebesar $74 \mathrm{HRF}$. Sedangkan kekerasan material campuran pada suhu sintering $550^{\circ} \mathrm{C}$ rata-rata sebesar 52 HRF. Dapat disimpulkan bahwa pemberian panas pada saat kompaksi dan pemilihan suhu sintering sangat berpengaruh terhadap kekerasan pada produk hasil proses metalurgi serbuk.
\end{abstract}

Kata kunci: aluminium; metalurgi serbuk; kompaksi bertahap; kekerasan

\begin{abstract}
The product resulting from the powder metallurgy process has advantages in terms of mechanical properties and physical properties. Material engineering by mixing several types of metal powders is very possible to do. The composition of this powder metallurgical process material is a mixture of aluminum powder (80\%), copper powder (15\%) and silicon carbide powder $(5 \%)$ by weight then compacted with a compaction load gradually, starting with a load of 3 tons, holding for 3 minutes, followed by a load of 3 tons. 4 tons were held for 3 minutes and the last 5 tons were held for 3 minutes by pre sintering $125^{\circ} \mathrm{C}$. Sintering in the kitchen with temperature variations of $450^{\circ} \mathrm{C}, 500^{\circ} \mathrm{C}$
\end{abstract}


and $550^{\circ} \mathrm{C}$ and sintering time for 60 minutes. Tests carried out on the specimens were hardness tests using the Rockwell (HRF) method. The results showed that the hardness of a single material has a hardness of around $35 \mathrm{HRF}$. The average hardness of the mixed material at a sintering temperature of $450^{\circ} \mathrm{C}$ is $80 \mathrm{HRF}$. The hardness of the mixed material at a sintering temperature of $500^{\circ} \mathrm{C}$ on average is $74 \mathrm{HRF}$. Meanwhile, the hardness of the mixed material at a sintering temperature of $550^{\circ} \mathrm{C}$ averaged $52 \mathrm{HRF}$. It can be concluded that the application of heat at the time of compaction and the selection of the sintering temperature greatly affect the hardness of the product resulting from the powder metallurgy process.

Keywords: aluminum; powder metallurgy; gradual compaction; hardness

\section{PENDAHULUAN}

Di Indonesia banyak sekali berdiri industri-industri besar dan kecil, dalam usaha pengembangan teknologi banyak upaya yang harus dilakukan yaitu dengan menciptakan karya baru dengan biaya yang murah, memiliki daya guna yang tinggi dan ekonomis. Namun pemanfaatan dan pengetahuan tentang cara pengolahannya masih kurang, sehingga material banyak yang terbuang percuma. Sehingga dituntut untuk bisa berkreativitas melalui pemikiran atau ide. Salah satunya dengan cara memanfaatkan bahan logam bekas atau geram untuk dibuat menjadi serbuk logam. Serbuk logam dapat diolah menjadi produk melalui proses pengepresan (kompaksi) dengan bantuan alat pemanas menjadi benda logam padat. Metalurgi serbuk merupakan proses pembuatan serbuk dan benda jadi dari serbuk logam atau paduan logam dengan ukuran serbuk tertentu tanpa melalui proses peleburan. Energi yang digunakan dalam proses ini relative rendah sedangkan keuntungan lainnya antara lain hasil akhirnya dapat langsung disesuaikan dengan dimensi yang diinginkan yang berarti akanmengurangi biaya pemesinan dan bahan baku yang terbuang. Yang menjadi masalah utama untuk memanfaatkan hasil serbuk tersebut adalah perlakuan-perlakuan terhadap serbuk logam tersebut engan sebaik-baiknya, sehingga menjadi sebuah benda yang mempunyai nilai yang tinggi ( Fauziati dan Arfina, 2010)

Untuk mendapatkan proses pemadatan yang sempurna proses kompaksi dapat dilakukan pada temperatur tinggi atau dikenal dengan istilah Hot Pressing. Pres dalam keadaan panas akan menjadikan serbuk menjadi lebih lunak/plastis, sehingga memudahkan untuk dipadatkan. Untuk itu pengaruh suhu pemanasan harus dapat terkontrol agar didapat produk yang homogeny. Kepadatan sangat berpengaruh sekali terhadap kekuatan dari produk yang dihasilkan. Ukuran partikel, bentuk dan distribusi ukuran serbuk logam mempengaruhi karakteristik dan sifat fisis dari benda yang dimampatkan. Serbuk dibuat menurut spesifikasi antara lain: bentuk, kehalusan, distribusi ukuran partikel, mampu alir (flowability), sifat kimia, mampu tekan (compressibility), berat jenis semu dan sifat-sifat sinter. Bentuk partikel serbuk tergantung pada cara pembuatannya, dapat bulau, tak teratur, dendritik,pipih atau bersudut tajam. Kehalusan berkaitan erat dengan ukuran butir dan ditentukan dengan mengayak serbuk dengan ayakan standar atau dengan pengukuran mikroskop. Ayakan standar berukuran mesh 36 sampai $850 \mu \mathrm{m}$ digunakan untuk mengecek ukuran dan menentukan distribusi ukuran partikel dalam daerah tertentu (Medi dan Karmiadji , 2010)

Distribusi ukuran partikel ditentukan berdasarkan jumlah partikel dari setiap ukuran standar dalam serbuk tersebut. Pengaruh distribusi terhadap mampu alir, berat jenis semu dan porosits produk cukup besar. Distribusi tidak dapat diubah tanpa mempengaruhi ukuran benda tekan. Mampu alir merupakan karakteristik yang menggambarkan sifat alir serbuk dan kemampuan memenuhi ruang cetak. Dapat digambarkan sebagai laju alir melalui suatu celah tertentu. Sifat kimia menyangkut kemurnian serbuk, jumlah oksida yang diperbolehkan dan kadar elemen lainnya. Kompresibilitas adalah perbandingan volum serbuk semula dengan 
volum benda yang ditekan. Nilai ini berbeda-beda dan dipengaruhi oleh distribusi ukuran dan bentuk butir. Kekuatan tekan mentah tergantung pada kompresibilitas. Berat jenis curah atau berat jernih serbuk dinyatakan dalam kilogram per meter kubik. Harga ini harus tetap, agar jumlah serbuk yang mengisi cetakan setiap waktunya tetap sama. Sinter adalah prose pengikatan partikel melalui proses pemanasan.

\section{Bahan}

\section{METODE}

Bahan yang akan digunakan dalam penelitian ini adalah limbah aluminium (bahan untuk rak, kusen). Selanjutnya bahan tersebut dibuat menjadi serbuk dengan cara digerinda dan kemudian diayak. Ukuran serbuk aluminium yang digunakan adalah $170 \mu \mathrm{m}$, Ditambahkan serbuk halus material lain yaitu $\mathrm{Cu}$ dan $\mathrm{SiC}$, dengan komposisi $\mathrm{Al}$ 80\%, Cu 15\% dan $\mathrm{SiC} 5 \%$ massa. Bahan dicampur dengan menggunakan magnetic stirrer dalam kondisi kering.Selanjunya pembuatan spesimen .

\section{Metode}

Pada proses pembuatan specimen dilakukan pembebanan kompaksi secara bertahap, mulai beban 3 ton ditahan 3 menit, dilanjutkan beban 4 ton ditahan 3 menit dan terakhir beban 5 ton ditahan 3 menit dengan pemanasan awal (pre sinter) $125^{\circ} \mathrm{C}$. Setelah proses kompaksi, selanjutnya spesimen disinter di dalam dapur dengan beberapa variasi temperatur yaitu 450,500 dan $550^{\circ} \mathrm{C}$. Waktu proses sintering selama 60 menit.
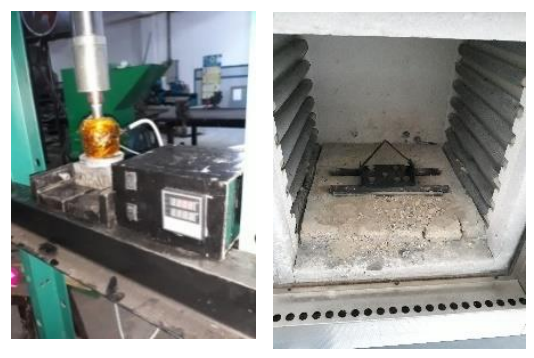

Gambar 1. Proses kompaksi (kiri) dan Proses sintering (kanan)

Setelah proses sintering selesai, specimen dikeluarkan dari dalam dapur dengan pendinginan udara. Pengujian yang dilakukan terhadap specimen adalah uji kekerasan permukaan dengan metode Rockwell (HRF) .

Uji

Pengujian yang dilakukan adalah pengujian kekerasan dengan metode Rockwell dengan terlebih dahulu specimen dihaluskan pada mesin polishing dengan menggunakan kertas gosok/amplas. Kertas gosok dengan grade agak kasar (grade 350), selanjutnya grade 500, 800 dan 1000. Mengatur beban penekan yang digunakan pada alat uji kekerasan yaitu beban $60 \mathrm{kgf}$. Indentasi pada setiap specimen sebanyak tiga titik dengan masing-masing variasi dilakukan pengulangan tiga kali. Bentuk specimen dibuat seperti koin, dengan sisi yang rata. Ukuran koin dengan diameter $18 \mathrm{~mm}$ dan ketebalan $10 \mathrm{~mm}$ seperti disajikan dalam gambar $2 \mathrm{a}$. 


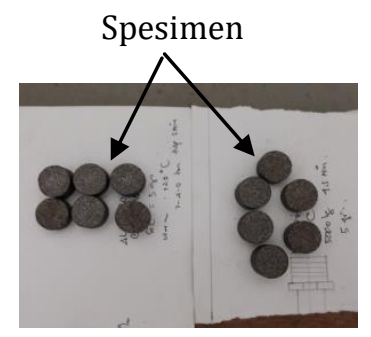

(a)

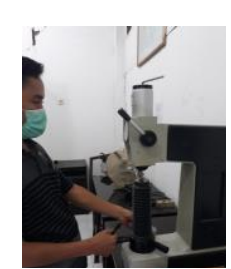

(b)

Gambar 2. a) Spesimen uji kekerasan, b) Mesin uji kekerasan

\section{HASIL DAN PEMBAHASAN}

\section{Analisa strukturmikro dari serbuk $\mathrm{Al}, \mathrm{Cu}$ dan $\mathrm{SiC}$}

Gambar 3a, 3b, dan 4 menunjukkan foto struktur mikro dari bahan baku serbuk Al, $\mathrm{Cu}$, dan SiC. Foto struktur mikro dari serbuk Al (warna putih) memperlihatkan sejumlah pori-pori (warna hitam) yang cukup banyak terlihat seperti disajikan dalam gambar 3a. Sejumlah pori-pori juga terlihat dalam serbuk $\mathrm{Cu}$ dan $\mathrm{SiC}$ seperti ditunjukkan pada gambar $3 \mathrm{~b}$ dan 4. Menurut Rusianto (2005), adanya sejumlah besar pori-pori tersebut diduga berkaitan dengan densitas dari masing-masing serbuk .

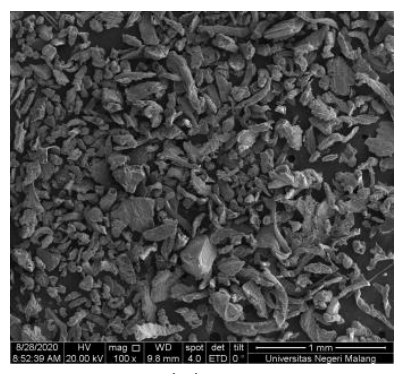

(a)

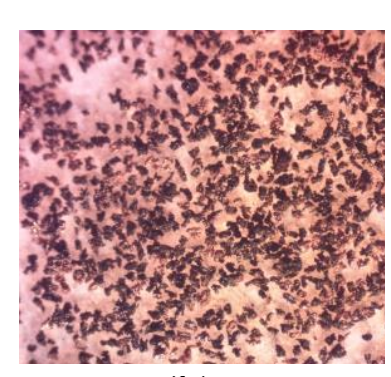

(b)

Gambar 3.(a) Serbuk aluminium $(\mathrm{Al})$, perbesaran 100x (b) Serbuk tembaga $(\mathrm{Cu})$, perbesaran 40x

Densitas sebuah bahan akan rendah ketika porositas dari bahan tinggi. Porositas yang ada pada bahan berada pada kondisi yang paling sedikit atau dapat dikatakan bahwa ikatan antar permukaan partikel pada kondisi yang paling baik. Hal ini juga menjawab alasan mengapa jumlah porositas dari serbuk Al terlihat lebih banyak daripada dua bahan serbuk lainnya, dikarenakan densitas serbuk $\mathrm{Cu}$ lebih rendah daripada dua bahan yang lainnya. Foto struktur dari serbuk $\mathrm{SiC}$ seperti disajikan pada gambar 4 ditemukan memiliki pori-pori yang lebih sedikit dibandingkan dengan dua bahan lainnya, hal ini disebabkan serbuk SiC kuat dan keras.

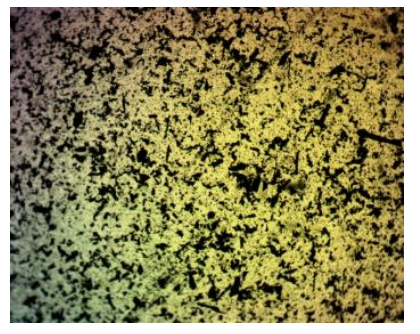

Gambar 4. Serbuk silicon karbida (SiC), perbesaran $40 \mathrm{x}$ 


\section{Analisa kekerasan bahan campuran Al/Cu/SiC}

Kekerasan material limbah aluminium murni ( tanpa campuran $\mathrm{Cu}$ dan $\mathrm{SiC}$ ) memiliki nilai rata-rata $35 \mathrm{HRF}$ dengan tingkat kemurnian 87,5\% dan sisanya dalam bentuk oksida logam pada kompaksi 1 tahap. Kompaksi 1 tahap diartikan pemberian beban secara langsung sebesar 5 ton dan ditahan 4 menit. Sedangkan kompaksi 3 tahap diartikan pemberian beban secara bertahap mulai 3 ton, 4 ton dan 5 ton dan masing-masing tahap ditahan selama 3 menit.

Nilai kekerasan ditunjukkan pada gambar 5. Nilai kekerasan pada specimen dengan kompaksi 1 tahap lebih tinggi dari kompaksi 3 tahap (namun tidak terlalu signifikan). Kondisi ini bisa jadi disebabkan karena proses penekanan secara langsung menyebabkan homogenitas yang lebih baik (porositas lebih kecil).

Nilai kekerasan dari bahan $\mathrm{Al} / \mathrm{Cu} / \mathrm{SiC}$ ditunjukkan pada gambar 5. Harga kekerasan bahan meningkat pada temperatur sintering kisaran $450^{\circ} \mathrm{C}$ dibandingkan bahan dengan sintering pada $550^{\circ} \mathrm{C}$. Nilai kekerasan paling tinggi diperoleh dari bahan pada temperatur sintering $450^{\circ} \mathrm{C}$ sebesar $80 \mathrm{HRF}$, kemudian diikuti oleh bahan $\mathrm{Al} / \mathrm{Cu} / \mathrm{SiC}$ pada temperatur $500^{\circ} \mathrm{C}$ dan $550^{\circ} \mathrm{C}$ masing-masing sebesar $74 \mathrm{HRF}$ dan $52 \mathrm{HRF}$. Peningkatan ini diduga terjadi karena partikel-partikel dari serbuk logam terikat satu sama lain dalam kondisi padat yang disebabkan kompaksi dan pemanasan,sehingga kekerasan bahan menjadi tinggi . Kekerasan aluminium maksimum sebesar 47 BHN diperoleh pada tekanan kompaksi optimum antara $162 \mathrm{Mpa}$ hingga $170 \mathrm{Mpa}$, suhu sinter optimum $500^{\circ} \mathrm{C}$ dan waktu sinter antara 40 sampai 50 menit. Pada pembuatan produk bantalan luncur dengan bahan paduan $\mathrm{Al}$ dan 5\% Grafit, diperoleh bahwa kekerasan maksimum diperoleh pada tekanan kompaksi 600 Mpa dengan holding time 180 menit yaitu $54,5 \mathrm{~kg} / \mathrm{mm}^{2}$ (Suanda, 2006) dan Safrudin et.al (2014). Hasil penelitian yang sama tetapi berbeda bahan juga telah dilaporkan dan dinyatakan bahwa interaksi antara partikel tungsten tembaga menjadi kuat dikarenakan kompaksi dan sintering (Safrudin et al. 2014).

Adanya unsur SiC di dalam logam berkontribusi pada kekuatan dan kekerasan bahan logam (Sari, 2018). Hasil penelitian yang sama dengan bahan yang sama tetapi berbeda pada saat kompaksi (tanpa penghangatan) dinyatakan bahwa temperatur sintering berpengaruh terhadap kekerasan (Triadi et al. 2019).

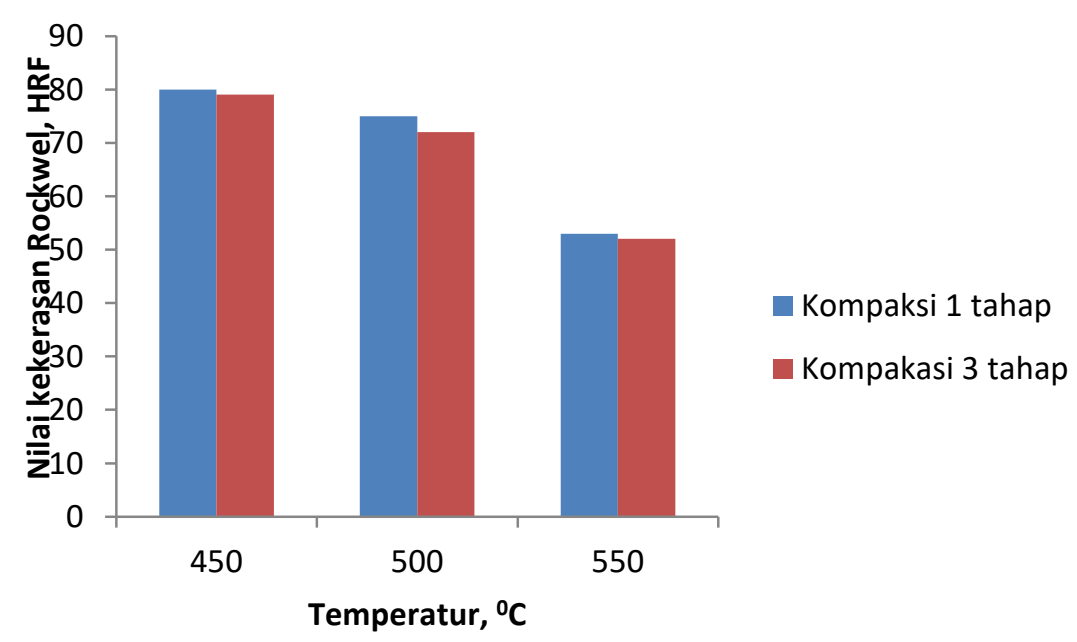

Gambar 5. Kekerasan bahan pada kompaksi single dan multi tahap dan variasi temperatur sintering 


\section{KESIMPULAN}

Tingkat kekerasan bahan campuran $\mathrm{Al} / \mathrm{Cu} / \mathrm{SiC}$ telah diteliti secara eksperimen. Sifat kekerasan bahan meningkat dengan meningkatnya temperatur sintering pada kisaran $450^{\circ} \mathrm{C}$ mencapai $80 \mathrm{HRF}$ daripada bahan yang disinter pada suhu $550^{\circ} \mathrm{C}$. Kekerasan bahan menurun ketika temperatur sintering $550^{\circ} \mathrm{C}$ Selanjutnya, penelitian ini perlu dikembangkan lagi untuk menyelidiki efek temperatur menggunakan suhu tinggi diatas $500^{\circ} \mathrm{C}$ dan waktu tahan sintering yang lebih lama.

\section{Ucapan Terima Kasih}

Penulis pada kesempatan ini mengucakan terimakasih kepada semua pihak yang membantu baik berupa materi maupun pikiran sehingga penelitian dan paper ini dapat terselesaikan. Yang kedua penulis mengucapkan terimakasih kepada Unram atas bantuan dana penelitian melalui program penelitian PNBP tahun 2020. Yang ke tiga penulis mengapresiasi Jurusan Teknik Mesin atas fasilitas yang dipergunakan dalam penelitian ini.

\section{DAFTAR PUSTAKA}

Fauziati dan Arfina, 2010. Sintesis MMCS Cu-A12O3 melalui Proses Metalurgi Serbuk dengan variasi Fraksi Volume AL2O3 dan Temperatur Sintering sebagai Bahan Alternatif Kelongsong Peluru, Surabaya : Teknik Material dan Metalurgi

Medi A dan Karmiadji DW, 2010. Pengaruh kompaksi dan kandungan grafit terhadap karakteristik mekanis bantalan luncur connecting rod, Forum Teknik, 33(2),125-130.

Rusianto, Toto, 2005. Pembuatan Bushing dari Bahan Serbuk Komposit Al/Al2O3 dengan variasi penambahan A12O3. Proseding Seminar Nasional ReTII di STTNas Yogyakarta. ISBN 979-99711-0-1.

Suanda T, 2006. Optimalisasi tekanan kompaksi, temperatur, dan waktu sintering terhadap kekerasan dan berat jenis aluminium pada proses pencetakan dengan metalurgi serbuk, Jurnal Ilmiah Semesta Teknika, 2 ( 9). 187-198.

Safrudin M., Yafiedan, Widyastuti, 2014. Pengaruh variasi temperature sintering dan waktu sintering terhadap densitas dan kekerasan pada MMC W-Cu melalui proses metalurgi serbuk, Jurnal Teknik Pomits, 3(1), 2337-3539.

Sari N.H., (2018) Material Teknik ,Edisi pertama, Deepublish, Yogyakarta, ISBN 9786024536718

Triadi A A., Yudhyadi IGNK., Suartika IM., Sari N.H., (2019). Efek suhu sintering terhadap sifat kekerasan dan kekuatan tekan bahan campuran $\mathrm{Al} / \mathrm{Cu} / \mathrm{SiC}$ melalui proses metalurgi serbuk, Jurnal Dinamika Teknik Mesin 9(2) 80-85 